\title{
SPECIAL ARTICLE \\ Conflicts of interest in orthopaedic surgery: The intertwining of orthopaedic surgery, peer review publications and corporate sponsorship
}

\author{
Dhillon KS, FRCS \\ KPJ Selangor, Specialist Hospital, Shah Alam, Selangor, Malaysia
}

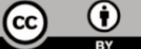 \\ Date of submission: November 2014 \\ Date of acceptance: February 2015
}

\begin{abstract}
Conflicts of interest in medicine has created deep concerns about the integrity of medicine and raised doubts about the trustworthiness of the medical professional. New stories of conflict of interest in medicine have become a commonplace. The interactions between the medical professional and the biomedical device as well as the pharmaceutical industry has become so pervasive that the primary interest of the medical professional in protecting and promoting the welfare of the patient has been compromised. The professional judgement and actions have been influenced by secondary interests, the major fungible and quantifiable being financial interest. The industry influence not only affects the way we practice orthopaedics but also affects medical education and peer review publications. Peer review publications have been shown to exaggerate benefits of the industry products while at the same time downplaying the risks. These conflicts of interest in orthopaedic surgery are particularly common in spinal and joint replacement surgery where joint replacement has been described as a 'fashion trade'. The introduction of new products appears to be an uncontrolled experiment which has been hijacked by large corporations. This article explores the unhealthy pervasive interaction between the orthopaedic surgeon and the medical devices as well as the pharmaceutical industry. It highlights how the biomedical and the pharmaceutical industry dominate all aspects of the healthcare system. With its wealth and political clout, its influence is present everywhere, from the use of devices and drugs, research, publications, trials, education and even formulation of CGPs.
\end{abstract}

Key Words:

Conflicts of interest, biomedical device and pharmaceutical industry, peer review publications, orthopaedic surgery, clinical practice guidelines.

\section{INTRODUCTION}

'...[C]onflicts of interest creates deep concerns about the integrity of medicine, medical research and raises questions about the trustworthiness of physicians, and medical institutions".

Over the last two decades or so there have been some unprecedented changes in the way that biomedical research is conducted and published. New stories about conflicts of interest in medicine have become a commonplace in the USA and Europe and this has created deep concerns about the integrity of medicine. Editorials such as 'Is academic medicine for sale?' have appeared in the prestigious New England Journal Medicine ${ }^{2}$. The conflicts of interest is pervasive in all medical disciplines and has not spared orthopaedic surgery where there is availability of huge corporate funding for biomedical research, publications and marketing. These concerns of conflict of interest have prompted the US congress, state legislatures and federal agencies to express their desire to see more stringent measures to be put in place to regulate the medical profession and medical institutions involved in biomedical research, medical education, and medical practice as well in the development clinical practice guidlines ${ }^{1}$.

\section{What is conflict of interest in medicine?}

The Institute of Medicine (IOM) 2009 report1 on conflict of interest in medical research, education and practice has eloquently defined conflict of interest as 'circumstances that create a risk that professional judgements or actions regarding a primary interest will be unduly influenced by a secondary interest'. Primary interest includes 'promoting and protecting the integrity of research, the quality of medical education and the welfare of the patient' while the secondary interests include 'financial interest', 'pursuit of professional advancement' as well as 'the desire to do favours for friends, family, students, or colleagues'. The 
major 'objective fungible and quantifiable' secondary interest is without doubt financial ${ }^{1}$.

There are many areas of orthopaedic practice where conflicts of interest are pervasive. This review will explore some of the areas of orthopaedic practice where it is has attracted the most public scrutiny and backlash.

\section{Spine surgeon and the medical device industry}

In the year 2001 in the United States, 122,000 lumbar fusions were carried out for degenerative disease of the spine and this represented a $220 \%$ increase from 1990 . This increase became more obvious after 1996 when fusion cages for spinal fusion became available. The increase in lumbar fusion from 1996 to 2001 was $113 \%$, while for hip and knee arthroplasty it was only $13 \%$ and $15 \%$ respectively ${ }^{3}$. Studies show that a higher proportion of fusion procedures and the introduction of new spinal implants between the years 1993 to 1997 did not reduce re-operation rates. In fact the reoperation rates were higher in the late 1990's as compared to the early 1990 's ${ }^{4}$. The cumulative incidence of reoperations for lumbar surgery for degenerative surgery is higher after fusion than spinal decompression alone ${ }^{5}$. It is well established that in symptomatic patients with spinal stenosis decompression of the spinal canal offers advantage over conservative treatment. However surgeons now offer fusion of the spine where a decompression of the spine would suffice. Deyo et $a l^{6}$ in a study of 32,152 Medicare patients with spinal stenosis undergoing surgery, found that although the surgical rates fell slightly between 2002 and 2007 , the rates of complex spinal fusions increased by 15 fold. The frequency of simple decompression and simple fusion reduced while complex fusion rates increased. The complex fusions were associated with increased risk of major complications, increased 30 day mortality and increased resources use. According to the authors the 15-fold increase in complex fusions in 6 years cannot be due to an increase in the number of patients with complex spinal pathology. They were of the opinion that introduction and marketing of new surgical devices and the influence of key opinion leaders is the likely reason for invasive procedures in the absences of new indications. Other possible reasons being financial incentives to hospitals and surgeons as well as the desire of surgeons to be innovators.

The influence of key opinion leaders and financial incentives for surgeons has hit the headlines in major US newspapers in recent years. Allegations of kickbacks to spine surgeons to use their products, relationship of surgeons to biomedical firms with financial arrangements involving this multibillion dollar industry have been highlighted ${ }^{7}$.

The Spine Journal, June issue 2011, gained attention from surgeons, researchers, patients, media, and industry when it focused attention on the controversial rhBMP-2 synthetic bone growth factor for use in spinal fusion surgery. It highlighted the limitation of industry sponsored research, bias in research development and reporting as well as weaknesses of peer review publications and inadequate disclosures and ethical shortcomings.

Recombinant human bone morphogenetic protein-2 (rhBMP-2), a bone growth factor was approved in 2002 by the FDA for single level anterior lumbar inter-body fusion with a threaded cage ${ }^{8}$. This approval was given even before the complex biological activities of the growth factor molecule were fully understood and to date it is still under study 9 . In fact, in 2002 Poynton and Lane ${ }^{10}$ had in a review article on the use of rhBMP-2, highlighted possible safety issues with this product. They wrote that;

'safety issues associated with use of bone morphogenetic protein in spine applications include possibility of bony overgrowth, interaction with exposed Dura, cancer risk, systemic toxicity, reproductive toxicity, immunogenicity, local toxicity, osteoclastic activation and effects on distal organs.'

However, they concluded that as far as the available data is concerned and if rhBMP-2 is used 'appropriately, placed accurately, not allowed to come in contact withdecompressed area and contained in the area of fusion' the use of rhBMP-2 is safe.

Notwithstanding the warning of possible safety issues with the use of rhBMP-2, around the same time, several small and large industry sponsored trials were published which highlighted the absences of any possible adverse events with use of rhBMP-2 in spinal surgery. In these industry sponsored publications 780 patients had received rhBMP-2 and the results were very similar in these studies with not even one adverse event reported ${ }^{11}$. The reported risk of adverse events in these publications, according to the review by Carragee et $a l^{11}$, was less than $0.5 \%$ with a $99 \%$ certainty which is one-fortieth the risk of adverse events with the use of NSAIDS or commonly used antibiotic ${ }^{11}$.

Although rhBMP-2 was approved by the FDA for use in a single level anterior interbody lumbar fusion, with the publication of such excellent results, surgeons extended the use of the product for off-label indications. In the US the use of rhBMP-2 increased from, in $0.7 \%$ of fusions in 2002 to $25 \%$ of fusions in $2006^{12}$. By 2007 rhBMP-2 was used in more than $50 \%$ of primary anterior lumbar inter-body fusions (ALIF), $43 \%$ of posterior lumbar inter-body fusion (PLIF)/ transforaminal lumbar inter-body fusions (TLIF) and in $30 \%$ of posterior lumbar fusions ${ }^{13}$. Smoljanovic et $a l^{14}$ attributed this rapid increase in the use of rhBMP-2 to the good results published by industry sponsored trials which showed virtually no adverse effects with the use of rhBMP2. Another reason for the increased use of rhBMP-2 was the reported complications of harvesting iliac crest bone graft (ICBG) by industry sponsored trials which reported $40 \%$ to $60 \%$ morbidity with harvesting of ICBG ${ }^{11}$. 
From 2006 however things started to change when several publications reported serious complications with the use of rhBMP-2. The reported rates of complications ranged from $20 \%$ to $70 \%{ }^{11}$ which prompted the FDA in 2008 to issue a public health notification of life threatening complication with the use of rhbmp-2 in the cervical spine ${ }^{15}$. The notification warned of the following complications:

'These complications were associated with swelling of neck and throat tissue, which resulted in compression of the airway and/or neurological structures in the neck. Some reports describe difficulty swallowing, breathing or speaking. Severe dysphagia following cervical spine fusion using rhBMP products has also been reported in the literature... Most complications occurred between 2 and 14 days post-operatively with only a few events occurring prior to day 2. When airway complications occurred, medical intervention was frequently necessary. Treatments needed included respiratory support with intubation, antiinflammatory medication, tracheotomy and most commonly second surgeries to drain the surgical site'.

Some of the complications reported by subsequent review of the original industry sponsored trials, data from the FDA and independent non-industry trials included; ${ }^{11}$

1. Use of rhBM-2 in ALIF

Osteolysis, subsidence and reoperations

Retrograde ejaculations

Urinary retention

Infections

2. Use of rhBMP-2 in PLIF

Overgrowth on spinal canal

Reoperations

Radiculitis, Osteolysis, loss of alignment

3. Use of rhBMP-2 in anterior cervical fusion

Osteolysis and loss of alignment

Spinal cord injury

Swelling, airway compromise, graft subsidence and endplate erosions, hoarseness and

dysphagia

4. Use of high dose rhBMP-2 and posterior-lateral lumbar fusion

Major back pain and leg pain

Increased risk of malignancy

A study by Vaidya et al in 2007 showed significant early (within 4 months) subsidence rates of more than $50 \%$ for lumbar fusions and $33 \%$ for cervical fusions, with the use of rhBMP-2 in inter-body vertebral fusions ${ }^{16}$. They also found a greater need for reoperation in the rhBMP-2 group as compared to allograft control group. Carragee and Wildstein in another study in 2007 found greater rates of graft subsidence and endplate failures with use of rhBMP-2 in the first four months after surgery as compared to control groups. The reoperation rates were also higher in the rhBMP2 group $^{17}$. Between 2002 and 2004 none of the industry sponsored trial publications reported these complications ${ }^{11}$ although data submitted to the FDA for regulatory evaluation in 2002 showed evidence that subsidence and implant displacement and loosening was more in the rhBMP-2 group as compared to controls ${ }^{18}$.

Similarly other complications such as retrograde ejaculation, urinary retention and infections were found to be higher with use of rhBMP-2 than the control groups, when a review of the original FDA data and non-industry publications was done, although these complications were not reported by the industry sponsored publications ${ }^{11}$. Bone overgrowth into spinal canal, radiculitis, osteolysis and loss of alignment complicating PLIF using rhBMP-2 were not reported by Haid et $a l^{19}$ in an incomplete industry sponsored trial. Similarly with use of rhBMP-2 in anterior cervical fusions the industry sponsored trials did not report the high rates of wound problems, soft tissue swelling, graft subsidence, endplate erosions and airway compromise, which was reported subsequently by non-industry sponsored trials ${ }^{11}$.

A review by Carragee et al11 of 13 industry sponsored published studies on the clinical efficacy and safety of rhBMP-2 in spinal fusion suggest that these publications underestimated or failed to report the adverse events associated with the use of rhBMP. The morbidity of harvesting iliac crest bone graft (ICBG) was exaggerated because of invalid methodology and assumptions. The methodology, surgical techniques and study designs were biased against the controls resulting in difficulty for the readers to assess the safety and efficacy of rhBMP. Furthermore the conflict of interest statements were 'vague, unintelligible or were internally inconsistent ${ }^{\prime 1}$.

The commonly cited reason for use of bone substitutes such as rhBMP is the morbidity associated with harvest of iliac crest bone. However a study by Howard et $a l^{20}$ showed that in patients undergoing posterior lumbar fusion the incidence of pain over the iliac crest was similar in patients who had graft harvested and those who did not have iliac graft harvested. In this study 112 patients had posterior lumbar fusion and iliac crest bone graft was harvested through the midline incision in 53 patients and in the other 59 patients rhBMP was used for fusion. An independent investigator not involved in the care of the patients analysed the results. There was no statistical difference in the number of patients having iliac crest tenderness in the two groups. Only 10 patients had tenderness and pain over the same crest from where graft was harvested.

In June 2011 the United States Senate Committee on Finance initiated an inquiry, after allegations surfaced that physician authors had failed to report adverse events related to the use of rhBMP-2 in spinal fusion. The inquiry was set up to determine whether Medtronic, Inc. had 'improperly influenced peer-review studies' of their product rhBMP-2 
(InFuse) in spinal fusion. The committee's sixteen month investigations revealed the following troubling evidence: ${ }^{21}$

- Medtronic was deeply involved in 'drafting, editing and shaping the contents' of the industry sponsored publications and the physician consultants involved in these publications had received significant amounts of money in royalties and consultancy fee from Medtronic. The role of the company in editing was not disclosed in the publications.

- The authors of these publications received \$210 million from Medtronic between 1996 and 2010 for consultancy and royalties besides other fees.

- An email by Dr Julie Bearcroft, an employee of Medtronic, involved in editing an article by Burkus et al for Journal of Bone and Joint Surgery (JBJS) 2005 recommended that 'significant detail' regarding adverse events should not be published in the article.

- Medtronic staff added input into the studies to emphasis the pain with autograft harvest to show that the rhBMP2 technique was better than harvesting iliac bone graft for spinal fusion.

- Dr Hallet Mathew, a well-known spine surgeon who appeared before the FDA advisory panel in 2002 for the clinical approval of rhBMP-2, had his expert testimony prepared by Medtronic. Though he claimed no financial relationship with Medtronic, subsequent investigations showed otherwise and in 2007 he was appointed vice president of Medtronic Spine Biologics' division.

The report concludes with a warning that peer reviewed publication should not 'downplay potential risk and exaggerate benefits of a product 'since that could put patients' lives at risk. The report admits that collaboration between scientists and industry is necessary but the publications should remain untainted by industry bias and the journals must aggressively insist on full disclosures to remain credible ${ }^{21}$.

This saga of conflicts of interest attracted extensive media coverage which questioned the integrity of medicine, medical research as well as the peer review publications, and at the same time it raised questions about the trustworthiness of physicians and medical institutions.

These conflicts of interest are not confined to spine surgery but extend to other areas of orthopaedic surgery where there is a close relationship between the surgeon and the multibillion dollar orthopaedic device manufacturing industry.

\section{Arthroplasty surgeon and the medical device industry}

Joint replacement has become what has been described as a 'fashion trade', which cost the health services tremendous amount of money and where the patient becomes a 'fashion victim'. Surgeons believe that expensive newer hips are better and the 'manufacturing companies ... scarcely let a year go by without introducing a "new improved" joint replacement which offer hitherto undreamt of (and unproved) advantages over older designs ${ }^{22}$.

The question this poses is whether the Charnley low friction hip arthroplasty has not lived up to its expectation? To the contrary, Charnley type prostheses have produced unprecedented, good long term outcomes which have given a new lease of life to millions of people around the world.

Two decades ago Neuman et $a l^{23}$ in a prospective study of 241 Charnley total hip replacements done between 1968 and 1974, using the first generation prosthesis and cementing technique, showed excellent long term results. The age of the patients ranged from 34 to 79 years and the mean follow-up was 17.6 years (15 to 20.6 years). Twenty two percent of the patients were below age of 55 years. A Kaplan-Meier survival analysis showed a $10.7 \%$ probability of revision at 20 years. The authors argued that a surgeon must 'justify his choice of technology by objective data...' and that they see 'no reason whatsoever to use expensive, sophisticated, often poorly documented designs on the basis of short term "success".

Malchau et $a l^{24}$ did a validation study of patients randomised from the whole of Sweden rather than from one centre (bias elimination) to evaluate the outcome of 169,419 primary hip replacements done from 1979 to 1998 . Of the 169,419 primary hip replacements, 158,614 were cemented, 5,559 were uncemented, and 5,246 were hybrid replacements. The revision rate of the cemented hips was $7 \%$ while for the uncemented hip was nearly double at $13 \%$. Polyethylene wear only accounted for $0.5 \%$ of the revisions. For aseptic loosening the 10 year survival for cemented hips using modern cementing technique was between 93 to $97 \%$. Despite the improvements in uncemented technology the results were still worse than the cemented hip replacements ${ }^{24}$.

Low risk of revision of metal on polyethylene bearing prostheses has continuously being reported by National Registries around the world, yet there is a rapid growth of technology offering alternative bearing surfaces, such as ceramic on ceramic and metal on metal, with the aim of reducing wear and hence delaying the time to revision. Serdrakyan et $a l^{25}$ in a comparative assessment of implantable hip devices with different bearing surfaces have shown that the revision rates of metal on metal and ceramic on ceramic are higher than those with traditional bearing surfaces using metal on polyethylene.

Despite excellent results with traditional hip replacements, new prostheses with fashionable design features and with theoretical superior performance continued to be launched into the market without extensive clinical testing.

In 1991 3M Healthcare launched the Capital Hip in the UK and within six years, 4,669 hips had been implanted in 
patients. This hip had a $19 \%$ to $21 \%$ failure rate at 5 years which is four times more than traditional hips ${ }^{26}$.

In early 1990's Polymers Reconstructive, Denmark, introduced the Boneloc cement with theoretical superior properties, to reduce aseptic loosening. The outcome was disastrous, with a fourteen times higher incidence of loosening as compared to the conventional cement ${ }^{27}$. Within one and a half years migration of the acetabular and femoral component was evident.

Early to midterm failures have been reported with other newer prostheses introduced into the market. The ProxiLock hip (Stratec Medical, Switzerland) was associated with early migration of the femoral stem and failure to stabilise on further follow-up with the uncoated stems $^{28}$. The Accord Knee (DePuy International Ltd, UK) showed very poor results at 8 to 10 years $^{29}$. The St. Leger knee (Covision, UK) though cheaper than other knee prostheses, the functional scores, knee scores and survivorship was poorer with this prosthesis when compared with the conventional peers ${ }^{30}$.

In August 2010, DePuy Orthopaedics, after pressure from various quarters, reluctantly, issued a voluntary recall of its metal on metal ASR ${ }^{\mathrm{TM}}$ XL Acetabular Hip System and DePuy ASR ${ }^{\text {TM }}$ Hip Resurfacing System ${ }^{31}$.

Cobalt toxicity and local tissue reaction leading to early failures (acetabular fractures, bone resorption, loosening and dislocation of prosthesis) of the McKee metal on metal hip has been known since $1975^{32}$. The Wagner metal on poly resurfacing hip introduced in 1978 was also a catastrophic failure $^{33}$. Genotoxicity of cobalt and chromium ion has been known since $1969^{34}$. Cobalt ion's link to cardiomyopathy has been known since $1966^{35}$, while hexavalent chromium as a proven carcinogen and trivalent chromium as a potential carcinogen, has been known since $1990^{36}$.

Despite previous failure of metal on metal prostheses and the known toxicity of metal ions that result from wear, new designs for metal on metal resurfacing hip began in Birmingham in 1989 and in 1991 the Birmingham resurfacing hip was first implanted. By 1997 this hip entered the European market (FDA approved it in 2006) and since it was proving popular Smith and Nephew acquired it. Not to lose the market share, DePuy came up with its ASR metal on metal resurfacing and total hip replacement prostheses which were introduced into Europe in 2003.

In 1996 Visuri et $a l^{37}$ had reported a 3.77 fold increase in the incidence of leukaemia in patients with metal on metal hips (McKee hips) as compared to conventional metal on polyethylene hips. In 1998 Haynes et al showed that particles of cobalt and chromium were toxic to monocytes in culture $^{38}$. Yet the sale of metal on metal hips continued and orthopaedic surgeons (including Malaysian surgeons) were eagerly joining the new wave of this 'fashion' trade.
In 2012, Deborah Cohen, the investigating editor of BMJ, reported on the evidence of risk from metal on metal hip devices, the lack of adequate response from manufactures to queries and the failure of regulatory bodies to provide the doctors and patients with the necessary information about these devices to help them make an informed decision. Her report highlighted that the average failure at 7 years of the resurfacing devices is $11.8 \%$ and $13.6 \%$ for the metal on metal hips compared to $3.3 \%$ to $4.9 \%$ for hip implants made from other materials ${ }^{39}$. The report also highlighted that while the normal blood levels of cobalt ion in healthy individuals is $0.5 \mu \mathrm{g} / \mathrm{L}$, with wear from the newer metal on metal hips it can reach levels over $300 \mu \mathrm{g} / \mathrm{L}$. Varying levels ranging from $0.7 \mu \mathrm{g} / \mathrm{L}$ to $217 \mu \mathrm{g} / \mathrm{L}$ have been reported with various makes of metal on metal prostheses such Pinnacle, ASR-XL, Duron and Birmingham hips ${ }^{39}$. Unfortunately, estimates show that in England and Wales over 60,000 and in the US over one million, metal on metal devices had been implanted since $2003^{39}$. The figures prior to 2003 were not available.

The report goes on to stress that a July 2005 DePuy internal memo revealed that DePuy was aware of 'potential changes in immune function' from metal debris, that the wear particles may be carcinogenic and of the possibility of distant effect of the debris. Despite these concerns, the marketing of these metal on metal devices by DePuy continued unabated. Even after the recall of ASR and ASR-XL in 2010, marketing of metal on metal devices continued in $2012^{39}$. There was regulatory failure by the FDA, European regulators and the Medicine and Healthcare Products Regulatory Agency (MHRA) of $\mathrm{UK}^{39}$. Cohen describes the saga of metal on metal devices as a 'large uncontrolled experiment' where 'carefully crafted surgical innovations fell into the hands of the powerful multinationals and shareholders intent trumped patient safety ${ }^{39}$.

The Australian, Therapeutic Goods Administration, Department of Health, after receiving data from the Australian joint registry, intervened and was the first country to get the ASR Hip recalled in Australia in 2009. DePuy did an international recall only in August 2010 after 93,000 hips had been implanted worldwide ${ }^{40}$. One of the surgeons involved in the development of the ASR Hip system, Dr Thomas Schmalzried in US had stopped using the hip in $2009^{41}$.

Dr Schmalzried received US \$20 million from DePuy as royalty for intellectual property in connection with development of the ASR and the Pinnacle Hip system between 2000 and $2013^{41}$. He received royalty payments for every hip implanted around the world (except those implanted in his hospital) and he continued to receive royalty payments even after he stopped using the implant in $2009^{41}$. Fifteen of his 66 (23\%) ASR-XL implanted had failed and needed revision. 
The saga of metal on metal hips with its increase in global burden of hip revisions and possible long term effect of the metal ions on the health of the patients have raised serious concerns among professionals and the public about the lack of regulatory framework as far as the introduction of joint replacement devices are concerned. A systemic review by Person et al showed that in England and Wales 24\% of all hip replacement implants available to the surgeons have no evidence of their clinical effectiveness ${ }^{42}$.

There is no doubt that for innovation in orthopaedic surgery physician-industry collaboration is necessary. However this physician-industry interaction has led to increasing conflicts of interest with diminishing scientific objectivity. Due to failure of industry, physicians and institutions to selfregulate, the US Department of Justice, in 2005, alleging violations of the Federal Anti-Kickback Statute began investigations of financial payments made to orthopaedic surgeons by five largest makers of joint replacement devices. These companies were accused of 'using consulting agreements with orthopaedic surgeons as inducements to use a particular company's artificial hip and knee reconstruction and replacement product's ${ }^{\prime 43}$. The investigations also revealed that, from late 1990 's to 2006, physicians who did little or no work of value for the companies were rewarded consulting contracts, lavish trips and other incentives. Furthermore the doctors did not reveal these financial arrangements to medical centres as well as to their patients ${ }^{43}$. Criminal complaints were filed against four companies (Zimmer, DePuy, Biomet, and Smith \& Nephew) who agreed to a deferred prosecution agreement. They also reached civil settlements with the Civil Division and Main Justice department and agreed to pay a combined total of \$311 million to settle claims under the Anti-kickback statute and Federal False Claims Act. The fifth company Stryker Orthopaedic received a non-prosecution agreement for its cooperation with the US attorney's office. These five companies accounted for $95 \%$, of the 5 billon dollars annual US sales and a 9 billion dollars worldwide sale, of the hip and knee replacement device market ${ }^{43}$.

In 2011, Johnson \& Johnson (J\&J) agreed to "pay a \$21.4 million criminal penalty as part of a deferred prosecution agreement with the Department of Justice to resolve improper payments by J\&J subsidiaries to government officials in Greece, Poland and Romania in violation of the Foreign Corrupt Practices Act (FCPA)'. The company admitted to making improper payments to public healthcare providers in these countries to purchase its devices and pharmaceuticals ${ }^{44}$. In 2011, in the UK, DePuy was also ordered by the court to pay almost $£ 5 \mathrm{~m}$ for unlawful payments in Greece between 1998 and 2006 ${ }^{45}$. Civil litigations and settlements involving the metals on metal hips are ongoing and the latest settlement reached was with Biomet in Feb 2014.
These new implants are a result of industry physician interaction which is often tainted with conflicts of interest. The new implants provide financial rewards for the industry and the surgeons involved, but unfortunately the patient becomes the victim of these innovations. The question that arises from this frequent failure of the newer implants is whether there is any way to prevent such catastrophic failures. The answer appears to be yes.

Sweden, where clinical roentgen stereophotogrammetic analysis (RSA) first originated, has one of the lowest revision rates in the world for hip and knee arthroplasty. Their success has been attributed to RSA and a meticulous follow up of the patients in their national arthroplasty registry. RSA is highly accurate to measure threedimensional migration of the prosthesis and it can show prosthesis translations of 0.2 to $0.3 \mathrm{~mm}$ and rotational migration between 0.2 to 1.2 degrees. Furthermore it only needs a short (1 to 2 years) follow up and a small cohort of 30 to 40 patients, to provide a detailed insight into the migratory behaviour of the prosthesis ${ }^{46}$. Nelissen et al showed a $22 \%$ to $35 \%$ reduction in the number of revisions of RSA-tested total knee replacements as compared with non-RSA-tested total knee replacements in the national joint registries of Sweden, Australia and New Zeland ${ }^{46}$. Implants with poor performance can be identified early with RSA and taken off the market at an early stage, hence preventing, widespread introduction of newer implants and large numbers of subsequent revisions. In fact, Nelissen has proposed a phased introduction of new implants which includes; (1) preclinical tests, (2) two-year clinical RSA trials, (3) larger multicentre clinical studies, and (4) post market surveillance in national registries. Without doubt this 'phased introduction of new prostheses, with RSA as an early qualitative tool, will establish safer and more effective patient care'46. National regulatory bodies should make passing a phased introduction test compulsory before allowing commercial use of any new prosthesis.

Newer prostheses are introduced with the hope that they last longer than the conventional prostheses, especially, in younger patients who need a joint replacement. However to date none of the newer designs have shown better results than the conventional designs. Schmitz et $a l^{47}$ have shown excellent results with cemented total hip replacement in patients younger than 30 years of age. In their cohort of consecutive 48 patients (69 hips) with a mean age of 25 years (range 16 to 29 years), 2 patients were lost to follow up. The 10 and 15 years survival rates with aseptic loosening as an endpoint was $90 \%$ and $82 \%$ respectively. None of their revisions needed a re-revision within 10 years after reimplantation.

Many surgeons are swayed by industry sponsored opinion leaders who travel around the world as guest lecturers. We need to remind ourselves that the results of joint replacement 
in a general setting may not be as good as that reported from specialist joint arthroplasty centres where these industry sponsored lecturers come from. Fender et al48 assessed independently the outcome of Charnley hip arthroplasty in 1,152 patients across a single health region in the UK in 1990. They found a failure rate of $9 \%$ at 5 years which is more than double that reported by the Scandinavian Registers. There is a need to remind surgeons that only tried and tested implants should be used in a general setting. Joint arthroplasty should only be done in specialist arthroplasty centres where possible and all patients after the surgery need to be followed up meticulously and a national joint replacement register should be established to give patients the best possible care.

Besides conflicts of interest between the orthopaedic surgeon and the medical device industry, there is another multibillion dollar industry with which the surgeons have to interact in their daily practice and it is the pharmaceutical industry.

\section{Orthopaedic surgeon and the pharmaceutical industry}

Just as many orthopaedic surgeons are interested in newer prostheses there is a corresponding interest in newer medications to treat diseases. However there is a need for caution in jumping on the bandwagon of newer therapies knowing that there is widespread conflict of interest in the relationship between physicians and the pharmaceutical industry.

In 1999 Merck introduced a new Cox-2 inhibitor, Rofecoxib (Vioxx), as a safe and efficacious alternative to other nonsteroidal anti-inflammatory drugs (NSAIDs) for treatment of osteoarthritis. Krumolz et al49 were able to access Merck's documents as a result of a tort ligation which showed startling conflicts of interest. In 1996-97, a Merck sponsored study revealed that Rofecoxib reduced urinary metabolites of prostacyclin in healthy individuals by half. Prostacyclin and its analogues are potent vasodilators and they possess antithrombotic activity. At the request of Merck the authors altered the manuscript to say that 'Cox-2 may play a role in biosynthesis of prostacyclin' instead of saying that the biosynthesis of prostacyclin synthesis was reduced by Rofecoxib $^{49}$. Despite the fact that Merck knew of the cardiovascular side effects of Rofecoxib, Merck in its new drug application to FDA in 1998, presented interventional studies that were 'generally small, had short treatment periods, enrolled patients at low risk of cardiovascular disease, and did not have a standardised procedure to collect and adjudicate cardiovascular outcomes ${ }^{49}$.

In January 1999, Merck launched its Vioxx gastrointestinal outcome research (VIGOR) study, involving over 8,000 patients to show its gastrointestinal (GI) safety compared to Naproxen in the treatment of rheumatoid arthritis. In this study, the first nonendpoint safety analysis of Vioxx showed a ' $79 \%$ greater risk of death or serious cardiovascular event' in one treatment group compared with the other ${ }^{49}$. Despite this finding, the safety monitoring board, which had some members on the board with conflicts of interest, allowed the study to continue till its GI endpoint. The study showed that Vioxx was not more effective than Naproxen in the treatment of Rheumatoid arthritis but the GI adverse effects were reduced by half. The outcome of the VIGOR trial was published in the New England Journal of Medicine in Nov 2000. The authors concluded that the incidence of myocardial infarction was lower in the Naproxen group but the rate of death from cardiovascular causes was the same in both groups ${ }^{50}$. Only 5 years later, in Dec 2005, an editorial appeared in the same journal expressing concern, after more data was available from a tort litigation, that there were inaccuracies and deletions in the data regarding cardiovascular risk of Vioxx, submitted to the journal in the original VIGOR manuscript ${ }^{51}$. In fact Mukherjee et al had in 2001 raised the 'cautionary flag' that the 'annualised myocardial infarction rates for cox-2 inhibitors (Vioxx and Celebrex) were significantly higher than that in the placebo group ${ }^{52}$. Merck, however, continued to investigate the use of Vioxx for other indications. In Feb 2000 the Adenomatous Polyp Prevention on Vioxx (APPROVe) trial began, to evaluate the reduction of risk of recurrent adenomatous colorectal polyps. It was a randomised, single blinded, placebo controlled trial. The study was terminated in September 2004, three months before the completion date because of increased incidence of myocardial infarcts and ischemic cardiovascular events ${ }^{53}$. Five of the authors of this study were Merck employees and the remainder who received consultancy fee asserted that the increased risks of cardiovascular events were seen only after an 18 months period. Further analysis of the data after publication showed that a flawed methodological approach was the reason for this conclusion $^{50}$. In 2006, more than a year after the publication of the APPROVe study in 2005 in the New England Journal of Medicine, a correction was published in the same journal to remove the statement that the increased risk of cardiovascular was apparent only after 18 months $^{54}$.

There were glaring failures of the peer review process of the medical journals. Flaws, mistakes and inaccuracies of Merck sponsored Vioxx publications escaped the peer review process of the New England Journal of Medicine which published both the VIGOR and the APPROVe studies. Articles favouring Vioxx, some of which were ghost written, appeared in several journals including the Annals of Internal Medicine and the journal Circulation ${ }^{50}$. Conflicts of interest were obvious but there was little outrage among the academics in this Vioxx saga which was bad news for industry, academics, journals, and the public ${ }^{50}$. In September 2004 Vioxx was withdrawn from the market while litigations and settlements between Merck and consumers are ongoing $^{55}$. 
In fact before the APPROVe trial began in early 2000, a Pfizer sponsored trial, the adenoma prevention with celecoxib (APC) trial had begun recruiting patients in November 1999. It was a large randomised controlled study to assess the effectiveness and safety of a Celecoxib 200mg twice a day, Celecoxib 400mg twice a day and placebo in reducing the incidence of colon and rectal polyps. After the findings of the APPROVe trial were known and the withdrawal of Vioxx in 2004, APC data and safety monitoring board, and the steering committee of APC requested a reassessment of data on cardiovascular safety by an independent committee. Based on the findings of the independent committee the use of Celecoxib in the remaining patients in the trial was stopped. The review of available data showed that there was a dose related increase in risk of cardiovascular events including deaths from myocardial infarcts, stroke and heart failure in patients on Celecoxib ${ }^{56}$.

The most scandalous failure of the peer review process was the case of Scott Ruben, a Professor of anaesthesiology in Boston, USA. He allegedly published 21 fraudulent articles, based on fabricated data, in leading peer review journals, including Anaesthesiology, Anaesthesia and Analgesia, and the Journal of Clinical Anaesthesia, among others, over a span of 13 years. The publications promoted the use of drugs such as Celebrex, Vioxx, Ketorolac, Oxycodone, and Pregablin, mainly in patients undergoing orthopaedic surgical procedures, while he had ties with the pharmaceutical industry ${ }^{57}$. In Feb 2010 he pleaded guilty to one count of healthcare fraud and the US Attorney's Office announced in June 2010, that Ruben was sentenced to 6 years in prison followed by 3 years supervised release and a $\$ 5,000$ fine, restitution of $\$ 361,932$ and forfeiture of $\$ 50,000^{58}$. This effectively ended his career as a doctor.

\section{Gifts, free lunches and the pharmaceutical industry}

Something is amiss in our healthcare system, which is highlighted by a complex, controversial and maybe unhealthy pervasive interaction between doctors and the pharmaceutical industry. This relationship starts in the medical school and continues through postgraduate training and last the lifetime of a physician ${ }^{59}$.

Moynihan has registered 15 forms of entanglement between the doctor and the pharmaceutical industry, ranging from trivial gifts (pens, pads), free meals, travel and accommodation expenses for 'educational' meetings, entertainment, trips, speaking honoraria, consultancy fee, and ghost writing of publications to name a few. Even medical journals and many medical societies interact and depend on corporate sponsorship ${ }^{60}$. This entanglement between doctors and industry is very widespread. Studies show that 80 to $90 \%$ of the doctors around the world regularly meet drug representatives and studies have also shown that the prescribing behaviour is influenced by gifts however trivial they are ${ }^{60}$. This interactions leads to a greater use of newer more expensive drugs and less use of generics despite lack of evidence of superiority of one over the other. It also leads to irrational and incautious prescribing behaviour $^{59}$. Continuing medical education (CME) tops the list of ways in which the pharmaceutical companies interact with the doctors. In the US, close to a billion dollars annually are spent by pharmaceutical companies on CME for doctors $^{59}$.

The Pharmaceutical companies claim that the cost of drugs is high because of the high cost of research and development (R\&D). Such claims appear to be untenable. Large drug companies apparently spend between 15 to $17 \%$ of their income on R\&D. The actual figures are not disclosed by the companies $^{61}$. However, after deduction of corporate tax the actual cost for R\&D should be lower. In the US, a major part of the initial research is done by academic centres, the government and other public and non-profit organizations. The National Institute of Health (USA) in 1995 found that 16 of the 17 key scientific papers that lead to the discovery and development of the five top selling drugs were from outside the pharmaceutical industry ${ }^{61}$. Most of the new drugs entering the market are modification of older drugs which are already in the market (called the 'me-too' drugs) ${ }^{61}$.

More money is spent by pharmaceutical industry on marketing than on R\&D. Up to about $36 \%$ of the big pharmaceutical company's budget is spent on marketing and distribution and this can be as much as 12 to 15 billion dollars annually according to some estimates ${ }^{61}$. Here is where the expenses for the entanglement between doctors and industry come from. In the USA there were 88,000 sales representatives, according to a 2002 estimate, who were paid about 7 billion dollars a year to promote drugs directly to doctors in the hospitals. This raises a question as to whether doctors really need to be educated about the use of the drugs by these representatives when all the information is readily available on the web at the touch of a button. It is not so much about the information the doctor receives from sales representatives but it appears to be more about the gifts, free lunches and other inducements which influence doctor's prescribing behaviour. CME meetings are also a major platform used by the industry to advertise their products to doctors. The influence of the industry does not end here but extends to other areas of medical practice.

Orthopaedic surgeons in their daily practice have to make clinical decisions about the most appropriate way to handle specific clinical circumstances based on valid scientific evidence and critical evaluation of the evidence. Such decisions can sometimes be difficult due to time constraints and the extensive volume of scientific literature available in a given field of orthopaedic surgery. Clinical practice guidelines can fill the void by providing the best available evidence, which will fulfil the needs of most surgeons, when 
they are faced with decisions about the most appropriate healthcare intervention.

\section{Orthopaedic surgeon and clinical guidelines}

Clinical practice guidelines are 'systematically developed statements to assist practitioners and patient decisions about appropriate health care for specific clinical circumstances". In clinical practice these guidelines 'influence patient and physician decision about healthcare intervention...', hence they should be based 'on valid scientific evidence, critical assessment of that evidence and objective clinical judgement' ${ }^{\prime}$. Practice guidelines were first proposed by the Institute of Medicine in $1990^{62}$. Since then the number of clinical practice guidelines (CPGs) have grown rapidly. Currently the US national guideline clearinghouse contains 2,564 individual guideline summaries on various topics including orthopaedics ${ }^{63}$. The American Academy of Orthopaedic Surgeons (AAOS) has currently published 14 CPGs and is in the process of developing further guidelines ${ }^{64}$. An AAOS guideline can take about 12 to 24 months to develop and these guidelines have to be updated on a regular basis to remain relevant.

Clinical guidelines must be based on the highest level of evidence with elimination of financial or other bias and they should not become a 'marketing tool for device and pharmaceutical manufactures ${ }^{95}$. When the biomedical and pharmaceutical industry and medical experts with affiliations to the industry, are involved in the development of clinical practice guidelines there can be conflicts of interest which may not be in the best interest of the patients and the healthcare providers.

In 2011, Norris et al did a systemic review of conflict interest in clinical practice guidelines development to 'describe the extent of conflict of interest (COI), both financial and intellectual, in clinical practice guidelines (CPGs) and to examine the effect of $\mathrm{COI}$ on recommendations within CPGs ${ }^{966}$. Their review included studies where there was prevalence of conflict of interest, industry relationships, funding, or sponsorship in CPGs or among guideline panel members and authors, or there was the effect of such conflicts on guideline recommendations. They were only able to identify 12 studies which met the criteria and this reflects the paucity of studies on this topic. However, their review found 'a high prevalence of nondisclosure of COI among authors across a variety of clinical specialties', and where there was disclosures a high percentage of CPG authors reported $\mathrm{COI}^{66}$. The authors recommended that users of CPGs 'need to critically appraise CPGs considered for implementation, read disclosures and consider how they may have influenced recommendations, and seek to move forward research on unanswered questions'.

Other studies have also found conflicts of interest in the development of clinical practice guidelines. Bindslev et al, in a study on conflicts of interest in the development of clinical practice guidelines found that disclosures were rare and conflicts of interest were common ${ }^{67}$. Choudhry et al in a survey of 192 authors of 44 CPGs found that there was considerable interaction between CPG authors and the pharmaceutical industry ${ }^{68}$.

The development of clinical practice guidelines can be a very sensitive issue, especially when the guidelines are created by a reputable state agency. The US Congress in 1989 created the Agency for Healthcare Policy and Research (AHCPR) after John Wennberg's research showed practice variation in the medical field and RAND studies showed widespread inappropriate use of common surgical procedures. The AHCPR was tasked with research on the outcome and effectiveness of treatment. One of its tasks was to produce clinical practice guidelines based on 'review and synthesis of available research, analysis of practice variations and patient outcomes ${ }^{\prime 69}$. Such research was conducted by Patient Outcome Research Teams (PORTs). One of the reasons for the near demise of such a useful agency was the result of conclusions of the PORT on low back pain. The PORT on back pain concluded that there was no evidence to support spinal fusion surgery for low back pain and that such surgery was frequently associated with complication ${ }^{69}$. The North American Spine Society attacked the literature review and initiated political lobby which resulted in 'rechristening' of AHCPR to the Agency for Healthcare Quality and Research (AHRQ) and the new agency withdrew from developing clinical practice guidelines ${ }^{1}$. Conflicts of interest in spinal surgery, especially in spinal fusion, as we now know are not uncommon $^{70}$.

Evidence based practice CPGs undoubtedly play a useful role. It is however not all doom and gloom with CPGs because of conflicts of interest. The AAOS has taken several steps to combat bias in the development of clinical practice guidelines. A full conflict of interest disclosure from all authors is mandatory and the AAOS uses 'systematic, welldefined processes that make it possible for readers to scrutinize every aspect of the decision-making that went into an AAOS clinical practice guideline'. Clinical physician experts and methodologists jointly construct the guideline and evaluate the evidence. The AAOS strives to make the guidelines unbiased, transparent, and reproducible ${ }^{71}$.

\section{CONCLUSION}

The biomedical and the pharmaceutical industry dominate all aspects of the healthcare system. With its wealth and political clout, its influence is present everywhere, from the use of devices and drugs, research, publications, trials, medical societies, medical associations, education and even formulation of CGPs. There is no doubt that industry-doctor relationship can have benefits but at the same time it can have serious consequences for the patient. It raises questions 
about professional trustworthiness and professional credibility.

These doubts about the professional trustworthiness exist because the professionals allow it to be so for various reasons, the most obvious being financial incentives. The industry cannot sell what doctors do not use and prescribe. In orthopaedic surgery, the older well established devices are more reliable and cheaper and most of the newer drugs in the market for orthopaedic use are not superior to the ones that have been there for a long time. A careful evaluation of the devices and drugs used in orthopaedic surgery will confirm this. If we carefully look at our own and our colleagues practice it will be obvious that incautious use of newer medications, with no known superiority over the existing drugs, is widespread. Incautious use of medications and devices is not only expensive for the healthcare system but also harmful to the very people we are trying to help, that is the patient.

The Physician Charter 2002 has among its set of professional responsibilities, a commitment to maintaining trust (of the patient) by managing conflicts of interest. Physicians are advised to resist the many available 'opportunities to compromise their professional responsibilities by pursuing private gain or personal advantage' when 'compromises are especially threatening in the pursuit of personal or organizational interactions with for-profit industries, including medical equipment manufacturers, insurance companies, and pharmaceutical firms ${ }^{972}$.
Guidelines on managing conflicts of interest have been promulgated by most medical associations, medical academic institutions and other health bodies such as the Institute of Medicine (US). Besides the comprehensive recommendations by the Institution of Medicine ${ }^{1}$, the Association of American Medical Colleges (AMMC) in 2010 has also produced a comprehensive report on managing conflicts of intrest ${ }^{73}$. However many medical colleges and institutions are still struggling to implement the recommendations of the report ${ }^{73}$.

Self-compliance does not appear to be the solution as has been highlighted above. It appears that government intervention is needed to scrutinise financial ties between medical professionals and the industry. Legislations in US, such as the federal Sunshine Law, False Claim Act and the federal Anti-Kickback Statute have helped to regulate some of these conflicts of interest.

Without doubt an ethical interaction between the medical professional and the industry is necessary to serve the best interest of the patient but it should not be tempered by conflicts of interest which bring harm to the patient. An appropriate approach has to be adopted to raise our profession from the present awkward, complex and murky situation that exists today. The choice is finally ours whether to solve the problem or to continue being part of it.

\section{REFERENCES}

1. Bernard Lo and Marilyn J Field. Editors, Committee on conflict of interest in medical research, education, and practice; Board on health science policy, Institute of Medicine USA 2009.

2. Angell M. Is academic medicine for sale? New Eng. J Med 2000; 342(20): 1516-8.

3. Deyo RA, Gray DT, Krenter W, Mirza S, Martin BI. United States trends in lumbar fusion for degenerative condition. Spine, 2005; 30(12): 1441-5.

4. Martin BI, Mirza SK, Cromstock BA, Gray DT, Krenter W, Deyo RA. Are lumbar spine reoperation rates falling with greater use of fusion surgery and new surgical technology? Spine 2001; 32(19): 2119-26.

5. Martin BI, Mirza SK, Cromstock BA, Gray DT, Krenter W, Deyo RA. Reoperation rates following lumbar spine surgery and the influence of spinal fusion procedures. Spine 2007; 32(30: 382-7.

6. Deyo RA, Mirza SK, Martin BI, Krenter W, Goodman DC, Jarvik JG. Trends, Major medical complications, and charges associated with surgery for spinal stenosis in older adults. JAMA 2010; 303(13): 1259-65.

7. Unneeded, risker spinal fusion on the rise. http://www.nbcnews.com/id/36197896/ns/healthhealth_ care/t/unneeded-riskierspinal-fusion-surgery-rise/\#.UtPJh_QW0aA. 
8. Dmitriev AE, Lehman RA, Symes AJ. Bone morphogenetic protein-2 and spinal arthrodesis: the basic science perspective on protein interaction with the nervous system. The Spine Journal 2011; 11: 500-5.

9. Heggeness MH. Commentary: Important considerations on bone morphogenetic protein-2 and neuroinflammation. The Spine Journal 2011; 11: 506.

10. Poynton AR, Lane JM. Safety profile for clinical use of bone morphogenetic proteins in the spine. Spine 2002 Aug $15 ; 27$ (16 suppl): 40-8.

11. Carragee EJ, Hurwitz EL, Weiner BK. A critical review of recombinant human bone morphogenetic protein-2 trials in spinal surgery: emerging safety concerns and lessons learned. The Spine Journal 2011; 11: 471-91.

12. Cahill KS, Chi JH, Day A, Claus EB. Prevalence, complications, and hospital charges associated with use of bone-morphogenetic proteins in spinal fusion procedures. JAMA 2009; 302: 58-66.

13. Ong KL, Villarraga ML, Lau E, Carreon L Y, Kurtz SM, \& Glassman S D. Off-label use of bone morphogenetic proteins in the United States using administrative data. Spine 2010; 35: 1794-800.

14. Smoljanovic T, Cimic M, Bojanic I. Aggressive end plate decortication as a cause of osteolysis after rhBMP-2 use in cervical spine inter-body fusion. Spine $J$ 2010; 10: 187-8

15. FDA Public Health Notification: Life-threatening Complications Associated with Recombinant Human Bone Morphogenetic Protein in Cervical Spine Fusion at http://www.fda.gov/MedicalDevices/Safety/AlertsandNotices/PublicHealthNotifications/ucm 062000.htm

16. Vaiddya R, Weir R, Sethi A, Meisterling S, Hakeos W, Wybo CD. Interbody fusion with allograft and rhBMP-2 leads to consistent fusion but early subsidence. J Bone Joint Surg Br 2007; 89: 342-5.

17. Carragee E, Wildstein M. A controlled trial of BMP and unilateral transpedicular Instrumentation in circumferential single or double level lumbar fusion. Spine J 2007; 7:8S-9S.

18. United States Food and Drug Administration, Department of Health and Human Services, Centre for Devices and Radiological Health. InFUSE bone Graft/LT-CAGE? Lumbar tapered fusion Devices-P000058. 2002. http://www.accessdata.fda.gov/scripts/cdrh/cfdocs/cftopic/pma/pma.cfm?num5P000058.

19. Haid RW, Branch CL, Alexander JT, Burkus JK. Posterior lumbar interbody fusion using recombinant human bone morphogenetic protein type 2 with cylindrical interbody cages. Spine J 2004; 4:527-38; discussion 538-9.

20. Howard JM, Glassman SD, Carreon LY. Posterior iliac crest pain after posterolateral fusion with or without iliac crest graft harvest. The Spine Journal 2011; 11: 534-7.

21. Staff Report on Medtronic's Influence on InFuse Clinical Studies, Committee on Finance, United States Senate, October 2012. http:/www.finance.senate.gov/imo/media/doc/Medtronic_Report1.pdf

22. Bulstrode CJK, Murray DW, Carr AJ, Pynsent PB, Carter SR. Designer Hips. BMJ 1993; 306: 732-3.

23. Neumann L, Freund KG, Sorenson KH. Long term results of Charnley total hip replacement: Review of 92 patients at 15 to 20 years. J Bone Joint Surg (Br) 1994; 76B: 245-51.

24. Malchau H, Herberts P, Soderman P, Oden A. Prognosis of total hip replacement: Update and validation of results from the Swedish National Hip Arthroplasty Register 1979-1998 at http://www.mcminncentre.co.uk/pdf/update-validation-results-fromswedish-hiparthroplasty-registry.pdf.

25. Sedrakyan A, Normand ST, Dabic S, Jacob S, Graves S, Marinac-Dabic D. Comparative assessment of implantable hip devices with different bearing surfaces: systemic appraisal of evidence. BMJ 2011; 343:d7434 doi:10.1136/bmj.d7434.

26. Muirhead-Allwood SK. Lessons of a hip failure. BMJ 1998; 316(7132): 644.

27. Thanner J, Freij-Larsson C, Karrholm J, Malchau H, Wessleu B. Evaluation of Boneloc. Chemical and mechanical properties and a randomized clinical study of 30 total hip arthroplasties. Acta Orthop Scand. 19955; 66: 207-14.

28. Luites JW, Spruit M, Hellemondt GG, Horstmann WG, Valstar ER. Failure of the uncoated titanium ProxiLock femoral hip prosthesis. Clin Orthop Relat Res. 2006 Jul; 448: 79-86.

29. Norton MR, Vhadra RK, Timperley AJ. The Johnson-Elloy (Accord) total knee replacement: Poor results at 8 to 12 years. Bone Joint Surg [Br] 2002; 84-B: 852-5. 
30. Gilbert RE, Carrothers AD, Gregory JJ, Oakley MJ. The St. Leger total knee replacement: a 10-year clinical and radiological assessment. Knee. 2009 Oct; 16(5): 322-5. doi: 10.1016/j.knee.2009.02.005.

31. DePuy. DePuy ASR hip recall guide at http://www.depuy.com/countries list.

32. Jones DA, Lucas HK, O'Driscoll M, Price CH, Wibberley B. Cobalt toxicity after McKee hip arthroplasty. J Bone Joint Surg Br. 1975 Aug; 57(3): 289-96.

33. Ashford RU, Frasquet-Garcia A, De Boer P and Campbell P. Catastrophic failure associated with Wagner resurfacing prosthesis and the impact on subsequent revision. J Bone Joint Surg Br 2008 vol. 90-B no. SUPP I 10.

34. Freeman MA, Swanson SA, Heath JC. Study of the wear particles produced from cobalt-chromium-molybdenum-manganese total joint replacement prostheses. Ann Rheum Dis 1969; 28(suppl): 29.

35. Barceloux D. Cobalt. J Toxicol Clin Toxicol 1999; 37: 201-16.

36. International Agency for Research on Cancer. IARC monographs supplement 7. 1990.

37. Visuri T, Pukkala E, Paavlainen P, Pulkinen P, Risha E. Cancer risk after metal on metal and polyethylene on metal hip arthroplasty. Clin Orthop \& Relat Res 1996; 329: S280-S289.

38. Haynes DR, Boyle SJ, Rogers SP, Howie DW, Vernon-Roberts B. Variation in cytokines induced by particles from different prosthetic materials. Clin Orthop 1998; 352: 223-30.

39. Cohen D. How safe are metal on metal implants? BMJ 2012; 344: e1410

40. DePuy Hip. Recall of DePuy orthopaedic ASR hip replacement device at http://www.tga.gov.au/newsroom/btn-dupuyrecall.htm\#.UvMFx_mSw_Y.

41. DePuy Hip. DePuy Hip developer says he wouldn't use implant. http://www.law360.com/articles/429627/depuy-hip-developersays-he-wouldn-t-use-implant.

42. Pearson FK, Ashmore AM, Malak TT, Rombach I, Taylor A, Beard D, Arden NK, Price A, Parieto-Alhambra D, Judge A, Carr AJ, Glyn-Jones. Primary hip replacement prostheses and their evidence base: systematic review of literature. BMJ 2013; 347:f6956 doi: 10.1136/bmj.f6956.

43. U.S. Department of Justice, U.S. Attorney's office, District of New Jersey, Office report 2002-2008. http://www.justice.gov/usao/nj/Press/files/pdffiles/2008/FinalWebpage1114.pdf.

44. U.S. Department of Justice. Johnson \& Johnson Agrees to Pay \$21.4 Million Criminal Penalty to Resolve Foreign Corrupt Practices Act and Oil for Food Investigations. http://www.justice.gov/opa/pr/2011/April/11-crm-446.html.

45. Cohen D. Out of joint: The story of ASR. BMJ 2011; 342: d2905.

46. Nelissen RG, Pijls BG, Kärrholm J, Malchau H, Nieuwenhuijse MJ, Valstar ER. RSA and Registries: The Quest for Phased Introduction of New Implants. J Bone Joint Surg Am. 2011 Dec 21; 93 Suppl 3: 62-5.

47. Schmitz M, Busch V, Gardeniers J, Hendriks J, Veth R, Schreurs V. Long term results of cemented hip arthroplasty in patients younger than 30 years and the outcome of subsequent revisions. BMC Musculoskeletal Disorders 2013, 14:37 doi: 10.1186/14712474-14-37.

48. Fender D, Harper WM, Gregg PJ. Outcome of Charnley total hip replacement across a single health region in England: the results at five years from a regional hip register. J Bone Joint Surg Br. 1999 Jul; 81(4): 577-81.

49. Krumholz HM, Ross JS, Prester AH, Egilman DS. What have we learnt from Vioxx? BMJ. 2007 January 20; 334(7585): 120-123. doi: 10.1136/bmj.39024.487720.68.

50. Bombardier C, Laine L, Reicin A, Shapiro D, Ruben Burgos-Vargas R, Davis B, Richard Day R, Ferraz MB, J. Hawkey CJ, Hochberg MC, Kvien TK, Schnitzer TJ, for the VIGOR Study Group. Comparison of Upper Gastrointestinal Toxicity of Rofecoxib and Naproxen in Patients with Rheumatoid Arthritis. N Engl J Med 2000; 343:1520-1528, DOI: 10.1056/NEJM200011233432103.

51. Curfman D, Morrissey S, Drazen JM. Expression of Concern: Bombardier et al., "Comparison of Upper Gastrointestinal Toxicity of Rofecoxib and Naproxen in Patients with Rheumatoid Arthritis," N Engl J Med 2000; 343:1520-8. N Engl J Med 2005; 353:2813-2814, DOI: 10.1056/NEJMe058314. 
52. Mukherjee D, Nissen SE, Topol EJ. Risk of cardiovascular events associated with selective COX-2 inhibitors. JAMA. 2001 Aug 22-29; 286(8): 954-9.

53. Bresalier RS, Sandler RS, Quan H, Bolognese JA, Bettina Oxenius B, Horgan K, Christopher Lines C, Riddell R, Morton D, Lanas A, Konstam MA, Baron JA, M.D. for the Adenomatous Polyp Prevention on Vioxx (APPROVe) Trial Investigators. Cardiovascular Events Associated with Rofecoxib in a Colorectal Adenoma Chemoprevention Trial. N Engl J Med 2005; 352:1092-1102, DOI: 10.1056/NEJMoa050493.

54. Correction. Cardiovascular Events Associated with Rofecoxib in a Colorectal Adenoma Chemoprevention Trial. N Engl J Med 2006; 355:221, DOI: 10.1056/NEJMx060029.

55. Merck settles new Vioxx claim, to pay $\$ 23$ million in settlement with consumers at http://www.nj.com/business/index.ssf/2013/07/merck_settles_vioxx_claim_to_p.html.

56. Solomon SD, McMurray JJV, Pfeffer MA, Wittes J, Fowler R, Fin P, Anderson WF, Zauber A, Hank E, Bertagnolli M. Cardiovascular Risk Associated with Celecoxib in a Clinical Trial for Colorectal Adenoma Prevention. N Engl J Med 2005; 352:1071-1080March 17, 2005DOI: 10.1056/NEJMoa050405.

57. Anesthesiology News. Fraud Case Rocks Anesthesiology Community: Mass. Researcher Implicated in Falsification of Data, Other Misdeeds at http://lcmedia.typepad.com/pharmola/2009/03/fraud-case-rocks-anesthesiologycommunity.html.

58. The United States Attorney's Office. Anesthesiologist sentenced on health care fraud charge. http://www.justice.gov/usao/ma/news/2010/June/Reuben\%20Scott\%20Sentencing\%20PR.html.

59. Blumenthal D. Doctors and drug companies. N Engl J Med 2004; 351: 1885-90.

60. Moynihan R. Who pays for the pizza? Redefining the relationships between doctors and drug companies. 1: Entanglement. $B M J$ 2003; 326:1189-92.

61. Relman AS and Angell M. How the drug industry distorts medicine and politics: America's Other Drug Problem. The New Republic: December 16, 2002: 27.

62. Committee to Advise the Public Health Service on Clinical Practice Guidelines / Institute of Medicine: Clinical Practice Guidelines: Directions for a New Program. Washington, DC: National Academy Press, 1990.

63. The National Guideline Clearinghouse: The National Guideline Clearinghouse at http://www.guideline.gov/browse/index.aspx?alpha=A.

64. The American Academy of Orthopaedic Surgeons: AAOS Evidence-based Clinical Practice Guidelines at http://www.aaos.org/research/guidelines/guide.asp.

65. Shaneyfelt TM, Centor RM. Reassessment of Clinical Practice Guidelines: Go Gently Into That Good Night. JAMA. 2009; 301(8): 868-869. doi:10.1001/jama.2009.225.

66. Norris SL, Holmer HK, Ogden LA, Burda BU. Conflict of Interest in Clinical Practice Guideline Development: A Systematic Review. PLoS ONE. 2011; 6(10): e25153. doi:10.1371/journal.pone.0025153.

67. Bindslev JBB, Schroll J, Gotzche PC, Lundh A. Underreporting of conflicts of interest in clinical practice guidelines: cross sectional study. BMC Medical Ethics 2013, 14:19 at http://www.biomedcentral.com/1472-6939/14/19.

68. Choudhry NK, Stelfox HT, Detsky AS. Relationships between authors of clinical practice guidelines and the pharmaceutical industry. JAMA 2002 Feb 6; 287(5): 612-7.

69. Gray BH, Gusmano MK, Collins SR. AHCPR and The Changing Politics Of Health Services Research. Health Affairs, no. (2003): doi: 10.1377/hlthaff.w3.283 at http://content.healthaffairs.org/content/early/2003/06/25/hlthaff.w3.283.citation.

70. See above section on spine surgeon and the medical device industry.

71. AAOS Evidence-Based Clinical Practice Guidelines: Frequently Asked Questions. http://www.aaos.org/Research/guidelines/Guideline_FAQ.asp.

72. Physician Charter: Advancing Medical Professionalism to Improve Health Care, http://www.abimfoundation.org/Professionalism/Physician-Charter.aspx.

73. AAMC Task Force Releases New Guidance on Managing Conflicts of Interest in Clinical Care August 2 , 2010. http://www.mwe.com/info/news/wp0810a.pdf. 